\title{
MEDIDAS LATINAS EM VERSO PORTUGUÊS
}

\author{
Érico Nogueira ${ }^{1}$ \\ ${ }^{1}$ Universidade Federal de São Paulo \\ São Paulo, São Paulo, Brasil
}

Resumo: Este artigo discute os principais métodos de adaptação de medidas latinas ao verso português, e esclarece os critérios que presidem a um método novo, exemplificado com tradução comentada da Ode IV 9 de Horácio.

Palavras-Chave: Métrica latina; Versificação portuguesa; Horácio.

\section{LATIN VERSE-LENGTHS IN PORTUGUESE}

\begin{abstract}
This paper both discusses the principal methods of reproducing Latin verse-lengths in Portuguese and explains the criteria of a new method, which it exemplifies by a translation and commentary of Horace's Ode IV 9.
\end{abstract}

Keywords: Latin metrics; Portuguese versification; Horace.

\section{A teoria}

A perda de sensibilidade à quantidade silábica ${ }^{1}$ e as múltiplas possibilidades de escansão e execução das mais variadas sequências rítmicas $^{2}$ - o hexâmetro inclusive ${ }^{3}$ - caracterizam a versificação latina

${ }^{1}$ Cf. SAnto AGOSTINHO, De Musica II, i, 1 ss.

${ }^{2}$ Ibidem IV, xiii, 18-19.

${ }^{3}$ Ibidem V, v, 9 ss. 
desde, pelo menos, a Antiguidade tardia, se não dantes ${ }^{4}$. A relação entre, de um lado, a longura e a brevidade das sílabas latinas e, do outro, os tempos marcados ou ictos responsáveis pela feição rítmica dos versos é problema espinhoso que não recebeu, até hoje, apesar de bastante discutido ${ }^{5}$, uma resposta definitiva. Escusando-nos, pois, de entrar nesse problema, e considerando, nos versos latinos, apenas e tão-somente a duração das sílabas, o icto ou acento mecânico, e o acento natural dos vocábulos (que, no entanto, a título de mera convenção, executaremos como acento expiratório, não melódico), podemos dizer que esses versos têm duas "pautas" distintas e superpostas, a primeira das quais constituída por ictos que imprimem um ritmo determinado a sílabas breves e longas, e uma segunda cujo ritmo se produz pela incidência de acentos tônicos numa sucessão de sílabas isócronas. Ou seja, enquanto na primeira o responsável por marcar o ritmo de determinada sequência de sílabas longas e breves é o que chamamos de icto, batida ou acento mecânico, na segunda, por sua vez, é o acento tônico natural das palavras quem dá certa feição rítmica a sílabas de duração mais ou menos igual.

Dessa maneira, o poeta ou tradutor moderno que se proponha a reproduzir um metro latino na sua língua deve antes de tudo e sobretudo escolher que pauta, afinal, se a primeira, a segunda ou ambas, pretende reproduzir. Vejamo-lo em maior detalhe, valendo-nos, para tanto, de um trecho das Geórgicas de Virgílio - que, sendo poesia hexamétrica, tem pés isócronos mas não isossilábicos - e de hexâmetros vernáculos de vários autores e de várias épocas, respectivamente.

(a) Virgílio, Geórgicas IV 1-12.

a) Leitura "reconstituída" ou à alemã ${ }^{6}$, atenta, quanto possível, à duração e ao icto das sílabas constantes do verso. Em latim,

\footnotetext{
${ }^{4}$ Cf. NICOLAU, 1934, passim.

${ }^{5}$ Cf. ALLEN, 1973, p. 129-199.

${ }^{6}$ Cf. KLOPSTOCK, 1989, p. 9-21 e VOSS, 1789, p. iii-xxiv.
} 
longas em negrito, breves sem marcação, ictos com acento agudo, elisões sublinhadas e número total de sílabas entre parênteses. Em português, tradução decassilábica de Leonel da Costa Lusitano (século XVII):

Prótinus áerií mellís | caeléstia dóna Logo do mel aéreo os dons celestes

(15) Prosseguirei. Também nesta, ó Mecenas, éxsequar: hánc etiám, | Maecénas, Parte (como nas mais) emprega os olhos: ádspice pártem.

(15) Dir-te-ei de leves cousas admirandos

Ádmiránda tibí | leviúm spectácula 'Spetáculos e capitães magnânimos rérum

(15) E per ordem os 'stúdios e costumes mágnanimósque ducés | totiús $\mid$ que De toda a gente, os povos e batalhas. órdine géntis móres ét studia ét | populós et

(16) Em sujeito mui fraco está o trabalho, próelia dícam.

Ín tenuí labor; át | tenuís | non glória, sí quem númina láeva sinúnt | audítque vocátus Apóllo. Mas a glória contudo não é fraca,

(16) Se consentem alguém os não propícios Deuses, e me ouve o já chamado Apolo.

(16) Há-se de buscar logo no princípio Às abelhas assento e estância certa, Príncipió sedés | apibús statióque pe (Porque tolhem os ventos às abelhas ténda, quó neque sít ventís | aditús |nam pábula vénti férre domúm prohibént $\mid$-neque ovés haedíque petúlci flóribus ínsultént | aut érrans búcula cámpo décutiét rorem ét $\mid$ surgéntes átterat hérbas.

b) Leitura tradicional ou à italiana ${ }^{7}$, respeitando apenas e tão-somente o acento natural das palavras. Tônicas em negrito; posição das sílabas acentuadas e número total de acentos indicados à direita.

Protinus aerii $\mid$ mellis caelestia dona $(1,6 ; 8,11,14=5)$ exsequar: hanc etiam, | Maecenas, adspice partem.

${ }^{7}$ Cf. D’OVIDIO, 1910, p. 323-327. 
Admiranda tibi | levium spectacula rerum $(3,5 ; 7,11,14=5)$ magnanimosque duces | totiusque ordine gentis $(4,6 ; 9,11,14=5)$ mores et studia et | populos et proelia dicam. $(1,4 ; 7,11,14=5)$ In tenui labor; at | tenuis non gloria, si quem $(2,5 ; 8,11,14=5)$ numina laeva sinunt | auditque vocatus Apollo. $(1,4,6 ; 9,12,15=6)$ Principio sedes | apibus statioque petenda, $(2,5 ; 7,11,14=5)$ quo neque sit ventis | aditus-nam pabula venti $(2,5 ; 7,11,14=5)$ ferre domum prohibent |-neque oves haedique petulci $(1,3,6 ; 10,13,16=6)$ floribus insultent | aut errans bucula campo $(1,5 ; 8,10,13=5)$ decutiat rorem et | surgentes atterat herbas.

$(2,5 ; 9,11,14=5)$

c) Comparação das leituras: respectivamente a reconstituída e a tradicional.

Prótinus áerií | mellís | caeléstia dóna

éxsequar: hánc etiám, | Maecénas, ádspice pártem.

Ádmiránda tibí | leviúm spectácula rérum

mágnanimósque ducés | totiús $\mid$ que órdine géntis

móres ét studia ét | populós et próelia dícam.

Ín tenuí labor; át | tenuís | non glória, sí quem

númina láeva sinúnt | audítque vocátus Apóllo.

Príncipió sedés | apibús statióque peténda, quó neque sít ventís | aditús | nam pábula vénti

férre domúm prohibént $\mid$-neque ovés haedíque petúlci

flóribus ínsultént | aut érrans búcula cámpo

décutiét rorem ét | surgéntes átterat hérbas.
Protinus aerii | mellis | caelestia dona

exsequar: hanc etiam, | Maecenas, adspice partem.

Admiranda tibi | levium spectacula rerum

magnanimosque duces | totiusque ordine gentis

mores et studia et | populos et proelia dicam.

In tenui labor; at | tenuis non gloria, si quem

numina laeva sinunt | auditque vocatus Apollo.

Principio sedes | apibus statioque petenda,

quo neque sit ventis | aditus-nam pabula venti

ferre domum prohibent | -neque oves haedique petulci

floribus insultent | aut errans bucula campo

decutiat rorem et | surgentes atterat herbas.

Falemos primeiramente do número e posição dos acentos no interior dos versos. Como se pode perceber, enquanto em a os ic- 
tos são sempre seis por linha, dispostos em andamento dactílico ou espondaico, em b as tônicas ficam entre cinco e seis, com sensível variação em suas posições iniciais e grande regularidade nas finais. Se, pois, no primeiro hemistíquio o icto ou acento mecânico de a e o acento natural de b em geral não recaem sobre as mesmas sílabas - ou pelo menos nem sempre -, a regra no segundo é que tais acentos coincidam, e os dois últimos com absoluta regularidade. Diferentes que sejam o número, a posição e a natureza dos acentos em a e em b, contudo, a tendência moderna de executar sílabas não isócronas de maneira isócrona - ou, dito de outro modo, a desconsideração ou ao menos a minimização da quantidade silábica na recitação de poesia antiga, hoje entre nós - tende a tornar as duas pautas bastante semelhantes entre si. Logo, independentemente do padrão acentual que se queira seguir (o dos meros ictos sem atenção à duração silábica ou o dos acentos tônicos), a real dificuldade - e a rara qualidade - de certas adaptações modernas de versos latinos está em simular, por meio de crases, elisões, sinéreses e vários expedientes afins, a duração ou quantidade silábica do modelo $^{8}$. Simulação ou sugestão que Pascoli chama de ritmo reflexo, e que, segundo ele, é a marca distintiva das melhores reproduções modernas de metros antigos, enfim ${ }^{9}$. Mas sigamos o argumento.

(b) Carlos Alberto Nunes, Eneida IV 1-5. Em português e em latim, ictos em negrito.

${ }^{8}$ Cf. HOPKINS, 2003, p. 124-128.

${ }^{9}$ Cf. PASCOLI, 2002, p. 239: “Os versos de Carducci, embora compostos de séries e hemistíquios vernáculos, têm a virtude de sugerir ao nosso espírito a lembrança dos antigos. Estes outros, tão regulares, nos farão no máximo lembrar de Ovídio; no máximo; - mas nem sequer Ovídio, porque a sucessão contínua de um heptassílabo, eneassílabo e pentassílabo, ou a de heptassílabo e outro heptassílabo, nos contenta assim: como uma estrofe vernácula qualquer. Contenta-nos assim, e nós ficamos aquém de Ilisso e do mar Egeu, e a estranhas plagas já não navegamos. Falta àquelas estrofes o 'ritmo reflexo'". Minha tradução. 
Quanto à Rainha, ferida | de cega paixão desde muito, nutre nas veias a chaga e $\mid$ no oculto braseiro se fina, a revolver de contínuo | na mente $o$ valor do guerreiro, a alta linhagem do herói; | no imo peito gravadas conserva suas palavras, o gesto. | De tantos cuidados não dorme.
At regina gravi | iamdudum saucia cura

vulnus alit venis | et caeco carpitur igni.

Multa viri virtus | animo multusque recursat

gentis honos; haerent $\mid$ infixi pectore vultus

verbaque nec placidam | membris dat cura quietem.

Bem: a circunstância de Carlos Alberto Nunes haver se escusado de substituir nenhum dáctilo por espondeu ou ao menos troqueu e, conseguintemente, haver tomado o hexâmetro holodactílico por modelo único mostra com suficiente clareza que, privilegiando o isossilabismo, e não propriamente a isocronia, buscou reproduzir tão-só os ictos do original - logo, sem atender à duração silábica - mediante o hábil agenciamento de tônicas e subtônicas portuguesas. Outra sensível diferença entre o hexâmetro latino e o seu vernáculo está no tratamento da cesura: lá, prevalecem as masculinas; cá, as femininas. Tudo somado, a recitação de seus versos tende a ser a ser monótona e monocórdica, a despeito do seu engenho, pioneirismo e riqueza vocabular ${ }^{10}$.

(c) Júlio de Castilho, "Hexâmetros". Em português e em latim, tônicas em negrito.
A bruma do alto mar $\mid$ some ao longe ao real foragido.
Protinus aerii | mellis | caelestia dona
Chora-o de pé na torre $\mid$ a constante, a misérrima Dido. exsequar: hanc etiam, | Maecenas, adspice partem.
Na tormenta cruel | que lhe agita as turbadas ideias, Admiranda tibi | levium spectacula rerum
Eneias brilha só: | triste Dido!, o teu mundo era Eneias! magnanimosque duces | totiusque ordine gentis

${ }^{10}$ Cf. OLIVA NETO, 2014. 
E Eneias vai cortando | (ímpia sorte!) as undosas campinas; superna mão lhe aponta | entre névoas as plagas latinas.

Nada espera nem vê: | se interroga o cerrado futuro,

se inquire o que lá vai, | só vê

Troia abrasada no escuro.

O marulho do oceano | os rugidos do incêndio arremeda, e os sibilos do vento | o estralar da fatal labareda. mores et studia et $\mid$ populos et proelia dicam.

In tenui labor; at | tenuis non gloria, si quem

numina laeva sinunt | auditque vocatus Apollo.

Principio sedes | apibus statioque petenda,

quo neque sit ventis | aditus, nam pabula venti

ferre domum prohibent, | neque oves haedique petulci.

Neste poema autoral de Júlio de Castilho, composto, com toda a probabilidade, para ilustrar a mudança de opinião de seu pai Antônio Feliciano, que na quarta edição do famoso Tratado de Metrificação Portuguesa passou a ser favorável à reprodução vernácula de medidas latinas e gregas ${ }^{11}$, o que se vê é a tentativa consciente de, admitindo alguma variação no primeiro hemistíquio mas sendo absolutamente regular no segundo, reproduzir a algo variável incidência dos acentos tônicos do hexâmetro latino, como bem exemplifica o mesmo passo das Geórgicas antes analisado. Resolvendo, pois, a irregularidade rítmica das três tônicas iniciais em três anapestos finais absolutamente regulares, pode-se dizer que Castilho procura seguir o encalço dos hexametricistas latinos, Virgílio incluso, que destacavam a chamada "cláusula hexamétrica" - isto é, os dois últimos pés do verso, em que há invariável coincidência entre o acento mecânico e o gramatical e, pois, o ritmo é consonante - dos ritmicamente mais variados e algo dissonantes pés anteriores, em que esses acentos tendem a não coincidir. Se, pois, por um lado, os hexâmetros de Castilho são mais interessantes e variados que os de Nunes, são-lhes, por outro, mais ou menos equivalentes, já que ambos desconsideram ou minimizam o efeito poético da quantidade silábica, e, portanto, reproduzem em português padrões acentuais exclusivamente qualitativos, atinentes

${ }^{11}$ Cf. CASTILHO, 1874 , p. 29-32. 
à mera tonicidade; padrões ritmicamente distintos, certo, mas nos dois casos de natureza expiratória.

(d) José Maria da Costa e Silva, "Epístola ao Doutor Vicente Pedro Nolasco da Cunha”, 19-29. Em português e em latim, tônicas em negrito.

De jugo livres, | livres d' accento tedioso ou breve ou tarda $\mid$ a marcha translado jucundo d'opostos Estos | d'alma d'Iliso, do Tibre , sublimes metros $\mid$ de seus antigos Poetas mil, que a Modernos | Vates faltaram, recursos deram; por empeços $\mid$ brioso o Gênio rompe;

Klopstock, o primeiro, ousou | com planta liberta,

saltando barreira, | correr por ínvia senda.

Germânicas vozes | desposa à Lira d'Homero,

Homero alcança | ou vence torrente profusa

dos Alpes despenhada | com hórrida queda.
Protinus aerii $\mid$ mellis | caelestia dona exsequar: hanc etiam, | Maecenas, adspice partem.

Admiranda tibi | levium spectacula rerum

magnanimosque duces | totiusque ordine gentis

mores et studia et $\mid$ populos et proelia dicam.

In tenui labor; at | tenuis non gloria, si quem

numina laeva sinunt | auditque vocatus Apollo.

Principio sedes | apibus statioque petenda, quo neque sit ventis $\mid$ aditus-nam pabula venti

ferre domum prohibent $\mid$-neque oves haedique petulci

floribus insultent | aut errans bucula campo $[\ldots]$.

Ainda mais próximos que os de Júlio de Castilho da que chamamos segunda pauta acentual dos versos latinos são estes hexâmetros de José Maria da Costa e Silva, sem dúvida. Com efeito, fazendo que o número de tônicas por verso oscile entre cinco e seis - distribuídas, porém, de tal modo que apenas as duas últimas tenham incidência regular -, Costa e Silva faz versos ritmicamente mais variados e, numa palavra, mais engenhosos que os de Júlio de Castilho, que, como vimos, das invariáveis seis tônicas que mete por linha varia apenas as três primeiras. Logo, no que toca ao número 
e posição dos acentos de intensidade (e à proximidade com o modelo latino), seus hexâmetros são mais perfeitos que os de Castilho filho, evidentemente; mas não só: porque, além de bastante próximos do original, quanto à distribuição dos acentos tônicos, eles são também ousada (e erudita) experimentação com quantidades silábicas supostamente portuguesas, e, desse modo, somando à segunda a primeira pauta, buscam, por fim, uma reprodução "integral" do modelo romano. Vejamo-lo em detalhe.

(e) José Maria da Costa e Silva, "Epístola ao Doutor Vicente Pedro Nolasco da Cunha", 19-29. Em português e em latim, longas em negrito, ictos acentuados e elisões sublinhadas.

Dé jugó livrés, | livrés d' accénto tedioso óu breve óu tardá a marchá | transládo jucundo

d'ópostós Estós | d'almá d'Ilíso, do Tíbre,

súblimés metrós | de séus antígos

Poétas

míl, que a Módernós | Vatés

faltáram, recúrsos

déram; pór empeçós | brióso o Génio rómpe;

Klópstock, ó priméiro, ousóu | com plánta libérta,

sáltandó barréira, | corrér por ínvia sénda.

Gérmânicás vozés | despósa à Líra d'Homéro,

Hómero álcança óu vencé | torrénte profúsa

dós Alpés despénhadá | com hórrida quéda.
Prótinus áerií | mellís | caeléstia dóna

éxsequar: hánc etiám, | Maecénas, ádspice pártem.

Ádmiránda tibí | leviúm spectácula rérum

mágnanimósque ducés | totiús $\mid$ que órdine géntis

móres ét studia ét | populós et próelia dícam.

Ín tenuí labor; át | tenuís | non glória, sí quem

númina láeva sinúnt | audítque vocátus Apóllo.

Príncipió sedés | apibús statióque peténda,

quó neque sít ventís | aditús | nam pábula vénti

férre domúm prohibént $\mid$-neque ovés haedíque petúlci

flóribus ínsultént | aut érrans búcula cámpo [...].

Conquanto os hexâmetros de Costa e Silva não se recitem à alemã, mas à italiana - isto é, realçando as cinco ou seis tônicas de cada sequência silábica, não os seis ictos de cada verso -, 
percebe-se que o seu autor, aplicando ao português as regras de longura silábica do latim, habilissimamente faz que os três ou quatro primeiros ictos não coincidam com o acento tônico dos vocábulos, os dois ou três finais coincidam, criando, assim, um artefacto novo, cujo molde é latino mas a matéria é portuguesa: artefacto híbrido, pois, como bem se vê, que depende de não pouca intimidade com a poesia e a versificação latinas para ser apreciado como convém. Finalmente, observemos agora lado a lado as duas pautas que se deixam ler nos versos de Costa e Silva, e façamos breves considerações finais sobre os métodos de reproduzir medidas latinas em português.

(f) José Maria da Costa e Silva, "Epístola ao Doutor Vicente Pedro Nolasco da Cunha”, 19-29. Pauta italiana [d] e pauta alemã [e], respectivamente.

De jugo livres, | livres d' accento tedioso ou breve ou tarda | a marcha translado jucundo

d'opostos Estos | d'alma d'Iliso, do Tibre , sublimes metros | de seus antigos Poetas

mil, que a Modernos | Vates faltaram, recursos

deram; por empeços | brioso o

Gênio rompe;

Klopstock , o primeiro, ousou | com planta liberta,

saltando barreira, | correr por ínvia senda.

Germânicas vozes | desposa à Lira d'Homero,

Homero alcança | ou vence torrente profusa

dos Alpes despenhada | com hórrida queda.
Dé jugó livrés, | livrés d' accénto tedioso -

óu breve óu tardá a marchá | transládo jucundo

d'ópostós Estós | d'almá d'Ilíso, do

Tíbre,

súblimés metrós | de séus antígos

Poétas

míl, que a Módernós | Vatés

faltáram, recúrsos

déram; pór empeçós | brióso o

Génio rómpe;

Klópstock, ó priméiro, ousóu | com plánta libérta,

sáltandó barréira, | corrér por ínvia sénda.

Gérmânicás vozés | despósa à Líra d'Homéro,

Hómero álcança óu vencé | torrénte profúsa

dós Alpés despénhadá | com hórrida quéda. 
Visando, pois, como sugerimos acima, a uma reprodução "integral" ou "total" do hexâmetro latino em português, pode-se conjecturar que Costa e Silva procedeu como seus modelos mais autorizados, e, portanto, compôs estes versos segundo o método propriamente latino de os compor - isto é, atendendo à longura e brevidade silábicas e à incidência dos ictos -, para depois recitá-los, contudo, consoante o costume do tempo, realçando suas sílabas tônicas. Em outras palavras, a que chamamos pauta alemã é aqui uma pauta silenciosa ${ }^{12}$, mais para o olho culto e informado que para o ouvido desprevenido, a qual, por sua vez, se propriamente não modifica a recitação e a audição, altera sim, e não altera pouco, a impressão - e com ela o juízo - que se tem desses versos.

Assim, deixando, por ora, de lado a legitimíssima possibilidade de estabelecer outras equivalências entre os versos latinos e os portugueses ${ }^{13}$, e supondo que ictos, duração silábica e acentos tônicos, se não tudo, são pelo menos o grosso do que há para reproduzir em versos latinos de qualquer medida, tem-se, afinal, que, 1) ou se reproduzem os ictos sem atender à duração silábica (o método de Carlos Alberto Nunes); 2) ou se replicam os meros acentos tônicos (o método de Júlio de Castilho); 3) ou se persegue uma reprodução integral, de acentos tônicos mais ictos com duração silábica, de versos que se compõem à latina mas se recitam à portuguesa (o método de Costa e Silva). Isso é tudo - e esgota a combinação dos elementos que se pretende reproduzir? Parece-nos que não.

De facto, partindo justamente do exemplo de Costa e Silva, pode-se pensar num método que 4) reproduzisse os ictos do modelo sem contudo descurar a duração silábica (a qual seria sugerida por sinéreses, elisões, crases e outros expedientes semelhantes) nem o efeito de contraste e dissonância causado pelos acentos tônicos, tomados aqui como pauta silenciosa, ou contraponto mais ou menos mudo, como o foram os ictos nos versos de Costa e Silva. Eis aí, descrito muito sumariamente, nosso método de reprodução verná-

\footnotetext{
${ }^{12}$ Cf. nota 9.

${ }^{13}$ Cf., p. ex., THAMOS, 2011.
} 
cula de Horácio - o qual, porém, apesar do esforço rigoroso, nem sempre conseguimos realizar, como logo veremos.

Realizado ou não, esperamos dilucidá-lo em detalhe nos breves comentários técnicos a nossa tradução da Ode IV 9, evidentemente. Frise-se também que o que aqui dissemos sobre um verso longo como o hexâmetro, complexo como nenhum na poesia latina e grega, vale também, mutatis mutandis, para a reprodução dos outros metros de Horácio (e não só os dele), e, se usamos exemplos hexamétricos, foi apenas e tão-somente por comodidade, graças à relativa abundância de hexâmetros portugueses, em contraste com a escassez de outros metros antigos.

\section{A prática}

Seguem-se, pois, lado a lado o texto latino da ode IV 9 e a reprodução vernácula que lhe demos. Note-se que marcamos as breves e as longas do original latino, assinalando os tempos fortes em negrito a fim de que se possa apreciar melhor a relação entre intensidade e longura silábica, essencial para o efeito poético de um tal texto. Em português, em negrito estão as tônicas, e em itálico, as subtônicas. Tanto lá como cá, sublinhamos apenas as sinéreses, crases e elisões mais importantes, e indicamos as principais cesuras com uma barra vertical.

\section{Ode IV 9}

Nē fōrtě crēdās | īntěrĭtūră quaē lōngē sŏnāntēm | nātŭs ăd Aūfîdūm, nōn āntě vōlgātās pěr ārtēs vērbă lŏquōr sŏcīāndă chōrdīs:

Nōn, sī prīōrēs | Maēŏnīūs těnēt 5 sēdēs Hŏmērūs, | Pīndărĭcaē lătēnt, Cēaēque, ět Ālcaēì mĭnācēs, Stēsǐchŏrīquě grăvēs Cămēnaē,
Não creias, não, que a | voz a calar-se venha que eu, nato ao pé lá $\mid$ do Áufido sonoroso, por artes cá sem precedentes solto das cordas acompanhado:

5 se sobe ao posto $\mid$ mais elevado o meônio Homero, nem de | Píndaro desparecem nem as de Ceos e Alceu minazes ou de Estesícoro grave as Musas, 
nēc, sī quĭd ōlīm | lūsǐt Ânācrěōn, dēlēvĭt aētās; | spīrăt ădhūc ămōrr, 10 vīvūntquě cōmmīssī călōrēs Aēǒlǐaē fîdǐbūs pŭēllaē.

Nōn sōlă cōmptōs | ārsĭt ădūltěrī crīnēs ět aūrūm | vēstǐbŭs îllǐtūm mīrātă rēgālēsquě cūltūs èt cŏmìtēs Hělěnē Lăcaēnā,

prīmūsvě Teūcēr | tēlă Cy̆dōnīō dīrēxĭt ārcū, | nōn sěměl Îllǐos vēxātă, nōn pūgnāvĭt īngēns İdŏměneūs Sthěnělūsvě sōlūs

dīcēndă Mūsīs | proēlǐă, nōn fẽrōx Hēctōr věl ācēr | Dēīphŏbūs grăvēs ēxcēpưt îctūs prō pŭdīcīs cōniŭgībūs pŭĕrīsquě prīmūs.

Vīxērě fōrtēs | ānte Ăgămēmnŏnă 25 mūltī; sěd ōmnēs | îllăcrīmābǐlēs ūrgēntŭr īgnōtīquě lōngā nōctě, cărēnt quĭă vātě sācrō.

\section{Paūlūm sěpūltaē | dīstăt ǐnērtǐaē} cēlātă vīrtūs. | Nōn ěgŏ tē měīs chārtīs ǐnōrnātūm sūlēbō, tōtvě tǔōs pătīār lăbōrēs

īmpūně, Lōllī, | cārpěrě līvǐdās ōblīvīōnēs. | Ėst ănǐmūs tǐbǐ rērūmquě prūdēns èt sěcūndīs tēmpǒrībūs dǔbīîsquě rēctūs,

vīndēx ăvāraē | fraūdǐs, ět ābstǐnēns dūcēntǐs ād sē $\mid$ cūnctă pěcūnǐaē, cōnsūlquě nōn ūnīŭs ānnī, sēd quŏtīēns bŏnŭs ātquě fīdūs

iūdēx hŏnēstūm | praētǔlĭt ūtǐlī, rēiēcǐt āltō | dōnă nŏcēntīūm vūltū, pěr ōbstāntēs cătērvās ēxplǐcŭît sŭă vīctǒr ārmă. nem o de outrora $\mid$ jogo de Anacreonte deliu a idade $\mid$ - e arfa inda hoje o amor e sobrevivem os calores

fiados à lira da moça eólia.

Não ardeu sozinha | quando do sedutor o penteado, os fios $\mid$ d'oiro naquelas vestes,

15 o aprumo e a comitiva reais inspecionou a espartana Helena,

nem Teucro foi quem | frechas lançou com o arco cidônio primeiro, | Ílion não só uma vez sitiou-se, não lutou sozinho

20 Idomeneu ou o ingente Esténelo

batalhas dignas | de musicarem-se ou o fero Heitor ou | Deífobo sevo, em honra da proba esposa e filhos, graves golpes levaram pioneiramente.

Viveram muitos | antes de Agamenão heróis, mas todos $\mid$ jazem inconsoláveis, em longa ignotos noite e opressos, porque carecem de um vate sacro.

Difere pouco a $\mid$ já sepultada inércia 30 Da proeza oculta. | Eu nestes meus papéis não vou deixar-te em branco e os teus tantos trabalhos sofrer quieto

que impunemente o | lívido oblívio os colha, ó Lólio, pois tens | 'spírito nos negócios

35 prudente e reto em circunstâncias já favoráveis já $d u$ biíssimas,

que vingador é | da ávida fraude e, puro do vil metal que | tudo após si atrai, é cônsul não de um ano só, se-

40 -não tantas vezes em que o honesto

prepôs ao útil, | bom e fiel juiz, e negou suborno, | cenho fechado, de corruptos, e entre imigas hostes vitorioso brandiu as armas. 
Nōn pōssǐdēntēm | mūltă vŏcāvěrīs 45 rēctē běātūm; | rēctǐŭs ōccŭpāt nōmēn běàtī, quī děōrūm mūněrǐbūs săpīēntěr ūtī

dūrāmquě cāllēt | paūpěrīēm pătī, pēiūsquě lētō | flāgĭtǐūm tǐmēt: nōn îllě prō cārīs ămīcīs aūt pătrīā tĭmĭdūs pěrīrē.
Àquele que tem | muito não chamarás feliz decerto; | tanto mais certo enverga o nome de feliz quem sabe as graças dos deuses utilizar

com siso e a dura, | sim, escassez' guentar e

50 melhor o Lete | julga que a ignomínia: que em prol de seus amigos caros ou bem da pátria morrer não teme.

\section{Comentário}

a. Constante de dois hendecassílabos, um eneassílabo e um decassílabo alcaicos, esta estrofe - a mais utilizada por Horácio em suas Odes - não tem ictos justapostos, o que facilita um pouco, sim, a sua replicação em português.

b. Sem embargo, a circunstância de que a sílaba ocupante da quinta sede do hendecassílabo - e, logo, imediatamente anterior à cesura - é sempre e invariavelmente longa deve ser levada em consideração, pelo que nos esforçamos, na sede portuguesa análoga, por colocar sílaba fechada, ditongo ou até gramaticalmente tônica, dotando-a, pois, do mesmo "peso" da latina: como, por exemplo, em “tem” (v. 45), "pouco a" (v. 29) e "é" (v. 37), entre outras.

c. O efeito contrastante de "iudex", por exemplo, cuja primeira sílaba, gramaticalmente acentuada, está fora do tempo marcado, foi reproduzido pelo vernáculo "com siso", em que "com", sendo indiferentemente átono ou tônico, pode sugerir tonicidade.

d. Os eneassílabos e decassílabos, desprovidos de cesura, não oferecem grandes desafios à sua reprodução vernácula - ao menos nesse aspecto.

e. Por outro lado, ao facto de que neles predomina a não coincidência entre tempo marcado e acento gramatical (isto é, abundam os efeitos contrastantes), a qual harmônica e engenhosamente se resolve na coincidência da última sílaba 
da estrofe, não encontramos um equivalente à altura, em português - a não ser, quem sabe, a pálida tonicidade de " $\underline{\text { de }}$ um" (v. 39), que faz as vezes de efeito contrastante.

f. Para o estilo, note-se a tentativa de seguir de perto a ordem latina dos vocábulos, e a longa sentença de quatro estrofes, do v. 29 ao v. 44, que reproduzimos em português.

\section{À guisa de balanço}

Tanto quanto pudemos averiguar, as principais dificuldades e desafios da reprodução vernácula de medidas horacianas estão, primeiro, na urdidura e confecção da pauta silenciosa (isto é, a dos acentos gramaticais que caem fora dos tempos marcados), segundo, na justaposição de sílabas tônicas, e, terceiro, na reprodução vernácula do estilo ou elocução originais, cujo traço, talvez, mais característico é a posição estratégica de cada palavra no interior dos versos, e a consequente longura e engenhosíssima articulação das sentenças entre si, com inúmeros parênteses e subordinações. Eis os três aspectos principais em que nossos brevíssimos comentários se concentraram - nos quais nos limitamos a um único exemplo de cada aspecto, diga-se desde já, que é o bastante para servir de guia a uma leitura atenta e juízo equânime dos nossos resultados.

É preciso confessar também que, se, por um lado, nos parece que vencemos sempre ou quase sempre as duas últimas dificuldades, fomos muito mais inconstantes e amargamos bastantes derrotas, ao enfrentar a primeira. Donde, nos comentários, nossa ênfase nos casos de vitória, deixando as muitas e patentes derrotas que falem por si, com uma ou outra exceção.

Se nossa tradução tem alguma novidade, portanto, ela está precisamente na tentativa - nem sempre bem lograda, repita-se - de replicar em português os tempos marcados do original sem esquecer o efeito contrastante dos acentos tônicos nem os característicos mais visuais que auditivos da elocução; o que não significa que não 
deva, e muito, ao precedente de Guilherme Gontijo Flores ${ }^{14}$, que em sua tese de doutoramento traduziu e comentou os três primeiros livros das Odes de Horácio buscando reproduzir os ictos e até o número de sílabas do original ${ }^{15}$.

\section{Referências}

ALlEN, W. Sydney. Accent and Rhythm. Cambridge: Cambridge University Press, 1973.

AURELIO AGOSTINO. De Musica. In: Tutti i Dialoghi. A cura di Giovanni Catapano. Milano: Bompiani, 2006. p. 1219-1652.

CASTILHO, Antonio Feliciano de. Tratado de Metrificação Portugueza: Seguido de Considerações sobre a Declamação e a Poetica. 4. ed. revista e aumentada. Porto: Livraria Moré-Editora, 1874.

COSTA E SILVA, José Maria da. Poesias de Joze Maria da Costa e Silva. Tomo III. Lisboa: Typ. de Antonio José da Rocha, 1844.

FLORES, Guilherme Gontijo. Uma poesia de mosaicos nas Odes de Horácio: comentário e tradução poética. 2014. 207 f. Tese (Doutorado em Letras Clássicas)

${ }^{14}$ Cf. FLORES, 2014.

${ }^{15}$ Com efeito, Flores pretendeu replicar em português o andamento rítmico ou a incidência de tempos marcados de seu modelo latino, criando versos que, como os originais, pudessem não só ser recitados mas também cantados com acompanhamento instrumental. Isso significa que certos característicos elocutórios mais visuais que propriamente auditivos dos versos de Horácio - tais como cesuras, a posição das palavras e o rebuscamento da sintaxe - não foram metodicamente reproduzidos em suas traduções, e isso pura e simplesmente porque a sua finalidade não está na mera leitura silenciosa ou na só recitação escolar (que ainda assim admitem, claro), senão, antes, no canto acompanhado de lira, cítara ou violão. 
- Faculdade de Filosofia, Letras e Ciências Humanas, Universidade de São Paulo, São Paulo, 2014.

KLINGNER, Friedrich (Ed.) Quintus Horatius Flaccus: Opera. 3. Auflage. Leipzig: Teubner, 1959.

KLOPSTOCK, Friedrich Gottlieb. Gedanken über die Natur der Poesie. Frankfurt: Insel, 1989.

NICOLAU, Mathieu. Les Deux Sources de la Versification Latine Accentuelle. $A L M A$, v. IX, [S.L], p. 55-87, 1934.

OLIVA NETO, João Angelo. O Hexâmetro Dactílico de Carlos Alberto Nunes: Teoria e Repercussões. Revista Letras, Curitiba, n. 89, p. 187-204, 2014.

D’OVIDIO, Francesco. Versificazione Italiana e Arte Poetica Medioevale. Milano: Hoelpi, 1910.

PASCOLI, Giovanni. Regole di Metrica Neoclassica. In: Scelte. Tomo Secondo. Milano: Arnoldo Mondadori Editore, 2002. . Poesie e Prose

THAMOS, Márcio. Do Hexâmetro ao Decassílabo: Equivalência Estilística Baseada na Materialidade da Expressão. Scientia Traductionis, Florianópolis, v. 10, p. 201-213, 2011.

VIRGíliO. Eneida. Tradução de Carlos Alberto Nunes. Organização de João Angelo Oliva Neto. São Paulo: Editora 34, 2014.

VOSS, Johann Heinrich. Des Publius Virgilius Maro Landbau. Hamburg: C. E. Bohn, 1789.

Recebido em: 28/04/2018

Aceito em: 18/07/2018 Publicado em setembro de 2018

Érico Nogueira. E-mail: nogueiraerico@gmail.com ORCID: https://orcid.org/0000-0002-3504-8376 